\title{
STRATEGI MANAJEMEN MUTU DI SMK KANSAI PEKANBARU
}

\author{
Indra Wahyuni (1) \\ Isjoni (2) \\ Zulfan Saam ${ }^{(3)}$
}

\author{
${ }^{1)}$ Post Graduate Student of Riau University \\ ${ }^{2)}$ Lecturer of Education Management Study Programme PPs University of Riau \\ ${ }^{3)}$ Lecturer of Education Management Study Programme PPs University of Riau
}

\begin{abstract}
This research aims to determine the quality management strategy at SMK Kansai Pekanbaru. This research is a qualitative research. The core informant in this research is the head of SMK Kansai Pekanbaru. As a control informant in this study are deputy principal of curriculum, vice principal of student field, vice principal of infrastructure, vice principal of public relations, teacher, school committee and student. Data collection techniques are done through observation, interview and documentation study. Researchers also conducted triangulation to compare observational data with data obtained from interviews and documentation. Then data obtained analyzed by using qualitative data analysis of interactive model consisting of data reduction, data presentation and conclusion. The result of the research shows that: (1) The quality management strategy that is planned, compiled and implemented SMK Kansai Pekanbaru in order to improve the quality of education is referring to the Total Quality Management (TQM) model, (2) The implementation process the principal supervises each month and performs Evaluation on an ongoing basis to see how much the level of achievement of the quality management strategy has been planned, (3) Factors supporting the implementation process of quality management strategy at SMK Kansai Pekanbaru is the educator who qualified S1 and S2 students according to the qualifications of the field he taught, (4) The process of implementation of quality management strategy at SMK Kansai Pekanbaru there are also inhibiting factors, there are still some teachers who do not want to cooperate in the case of improving the quality of school (5) To overcome the principal obstacle factors can overcome by giving rewards to teachers who discipline and carry out their main duties well in order to improve the quality of school.
\end{abstract}

Key words: Quality management strategy, vocational high school, total quality management

ABSTRAK: Penelitian ini bertujuan untuk mengetahui strategi manajemen mutu di SMK Kansai Pekanbaru. Penelitian ini merupakan penelitian kualitatif. Informan inti dalam penelitian ini adalah kepala SMK Kansai Pekanbaru. Sebagai informan kontrol dalam penelitian ini adalah wakil kepala sekolah bidang kurikulum, wakil kepala sekolah bidang kesiswaan, wakil kepala sekolah bidang sarana prasarana, wakil kepala sekolah bidang hubungan masyarakat, guru, komite sekolah dan siswa.Teknik pengumpulan data yang dilakukan adalah melalui observasi, wawancara dan studi dokumentasi. Peneliti juga melakukan triangulasi untuk membandingkan data hasil pengamatan dengan data yang diperoleh dari wawancara dan dokumentasi. Data yang didapat kemudian di analisis dengan menggunakan analisis data kualitatif model interaktif yang terdiri dari reduksi data, penyajian data dan kesimpulan. Hasil penelitian menunjukkan bahwa : (1) Strategi manajemen mutu yang direncanakan, disusun dan diimplementasikan SMK Kansai Pekanbaru dalam rangka meningkatkan mutu pendidikan adalah mengacu pada model Total Quality Management (TQM), (2) Dalam proses implementasi kepala sekolah melakukan supervisi setiap bulannya dan melakukan evaluasi secara berkesinambungan untuk melihat 
seberapa besar tingkat ketercapaian strategi manajemen mutu yang telah direncanakan, (3) Faktor pendukung proses implementasi strategi manajamen mutu di SMK Kansai Pekanbaru adalah tenaga pengajar yang berpendidikan kualifikasi S1 dan S2 orang sesuai dengan kualifikasi bidang studi yang diajarkannya, iklim sekolah dan lingkungan masyarakat yang kondusif serta sarana dan prasarana sekolah, (4) Dalam proses implementasi strategi manajemen mutu di SMK Kansai Pekanbaru juga terdapat faktor penghambat, yaitu masih terdapat beberapa guru yang tidak mau untuk bekerjasama dalam hal peningkatan mutu sekolah dan (5) Untuk mengatasi faktor penghambat kepala sekolah dapat mengatasi dengan cara memberikan reward kepada guru yang disiplin dan menjalankan tugas pokoknya dengan baik guna meningkatkan mutu sekolah.

Kata kunci : Strategi manajemen mutu, sekolah menengah kejuruan, total quality management

\section{PENDAHULUAN}

Upaya untuk meningkatkan kualitas pendidikan khususnya pendidikan menengah kejuruan sebenarnya memerlukan waktu yang panjang, rangkaian proses yang kompleks, teratur serta sistematis karena terkait dengan berbagai aspek kehidupan. Sekarang ini, mutu menjadi satu-satunya hal yang sangat penting dalam peningkatan kualitas pendidikan. Sayangnya, kebanyakan sekolah masih memandang bahwa mutu akan meningkat hanya jika masyarakat bersedia memberi dana yang lebih besar. Padahal dana bukanlah hal utama dalam perbaikan mutu pendidikan (Arcaro, 2006).

Era globalisasi menuntut adanya perubahan paradigma dalam dunia pendidikan. Untuk melakukan hal tersebut, peranan manajemen pendidikan sangat signifikan untuk menciptakan sekolah-sekolah bermutu. Peningkatan kompetisi, pilihan dan tuntutan pelanggan pendidikan mempengaruhi pendidikan saat ini (Ibnugraha, 2012). Selain itu perkembangan zaman juga semakin menuntut kualitas sumber daya manusia yang lebih modern dan berkualitas, hal tersebut akan berpengaruh terhadap suatu lembaga pendidikan (Munir, 2014).

Sekolah perlu meningkatkan mutu dalam sistem penyelenggaraan pendidikannya yang disesuaikan dengan perkembangan tuntutan masyarakat yang dianggap sesuai dengan tolak ukur norma ideal dan mewujudkan kebutuhan dan kepuasan pelanggan. Zamroni mengatakan, peningkatan mutu sekolah adalah suatu proses yang sistematis yang terus menerus meningkatkan kualitas proses belajar mengajar dan faktorfaktor yang berkaitan dengan itu, dengan tujuan agar target sekolah dapat dicapai dengan lebih efektif dan efisien (Zamroni, 2007).

Mulyasa (2007) menyatakan bahwa sekolah dapat dikatakan bermutu apabila prestasi sekolah khususnya prestasi peserta didik menunjukkan pencapaian yang tinggi dalam beberapa hal, diantaranya: 1) prestasi akademik, 2) memiliki nilai-nilai kejujuran, ketaqwaan, kesopanan, dan mampu mengapresiasi nilai-nilai budaya, 3) memiliki tanggung jawab yang tinggi dan kemampuan yang diwujudkan dalam bentuk keterampilan sesuai dengan dasar ilmu yang diterimanya di sekolah. Menurut Danim (2007) peningkatan mutu sekolah dapat dilakukan dengan melibatkan lima faktor yang dominan, antara lain : 1) kepemimpinan kepala sekolah, 2) siswa, 3) guru, 4) kurikulum, dan 5) jaringan kerjasama.

Dalam konteks pendidikan di SMK, penerapan prinsip-prinsip manajemen mutu mampu meningkatkan kualitas budaya sekolah (kultur sekolah). Saat ini sebagian besar SMK telah menerapkan sistem manajemen mutu berstandar ISO 9001:2008 yang diakui secara internasional. Hal ini diindikasikan dari banyaknya SMK yang telah memperoleh sertifikat ISO 9001:2008. Salah satunya adalah SMK Kansai Pekanbaru.

Dasar sertifikat ISO 9001:2008 ini yang membawa SMK Kansai Pekanbaru telah dipercaya oleh masyarakat dan mampu bersaing di dunia kerja. Hal ini dibuktikan dengan 
banyaknya siswa yang prestasi dibidang akademik dan non akademik serta banyaknya siswa lulusan SMK Kansai Pekanbaru yang diterima di perusahaan-perusahan. SMK Kansai Pekanbaru merupakan salah satu SMK swasta favorit di Pekanbaru yang memiliki sarana dan prasarana yang lengkap untuk menunjang kegiatan pembelajaran. SMK Kansai juga telah menjalin kerjasama dengan berbagai perusahaan seperti PT Yamaha dan Astra. SMK Kansai Pekanbaru memiliki keistimewaan dibandingkan dengan SMK swasta lainnya, yaitu adanya pembiasaan bahasa Jepang oleh siswa, guru maupun pegawai di SMK Kansai Pekanbaru. Hal ini dilakukan karena SMK Kansai Pekanbaru juga melakukan kerjasama dengan pihak Jepang yang bernama Bapak Kasugiro Ueno yang merupakan salah satu tokoh pendidikan di Jepang. Beliau adalah seorang penerjeman di Universitas Saku Toku Tokyo.

Berdasarkan prestasi dan kerjasama yang telah diperoleh, tentunya SMK Kansai memiliki strategi-strategi dalam pengelolaan sistem manajemen mutu guna mencapai hasil tersebut. Sehingga tujuan darri penelitian ini adalah untuk mengetahui strategi manajemen mutu di SMK Kansai Pekanbaru.

\section{METODE PENELITIAN}

Penelitian ini merupakan penelitian kualitatif. Penelitian dilakukan di SMK Kansai Pekanbaru dengan informan inti d adalah Kepala SMK Kansai Pekanbaru dan informan kontrol adalah wakil kepala sekolah bidang kurikulum, wakil kepala sekolah bidang kesiswaan, wakil kepala sekolah bidang sarana prasarana, wakil kepala sekolah bidang hubungan masyarakat, guru, siswa dan komite sekolah.Teknik pengumpulan data yang digunakan, yaitu (1) studi dokumentasi, wawancara, dan (3) observasi. Data yang didapat di analisis dengan menggunakan analisis data kualitatif model interaktif dari Miles dan Huberman yang terdiri dari (1) reduksi data, (2) penyajian data, (3) kesimpulan. Untuk pengujian keabsahan data dilakukan menggunakan teknik triangulasi.

\section{HASIL DAN PEMBAHASAN}

\section{Strategi Manajemen Mutu di SMK Kansai Pekanbaru}

Dari penggalian data tentang strategi manajemen mutu di SMK Kansai Pekanbaru, ada beberapa program dan aktifitas yang dilaksanakan SMK Kansai Pekanbaru dalam rangka pelaksanaan strategi manajemen mutu di sekolah, salah satunya selalu berupaya semaksimal mungkin untukmeningkatkan kualitas guru. Hal tersebut dapat dilakukan melalui kegiatan pelatihan-pelatihan, workshop, orientasi dan seminar tentang pendidikan, atau mengirim guru sebagai peserta dalam kegiatan tersebut, baik yang dilaksanakan oleh sekolah maupun dinas atau instansi lain. Selain itu dapat dilakukan dengan memberikan arahan dan bimbingan dalam setiap pertemuan bulanan kepada guru serta melakukan monitoring dan evaluasi terhadap pelaksanaan tugas guru dan pegawai, baik pengawasan dalam pelaksanaan tugas mengajar maupun pengawasan dalam hal tingkat kedisiplinan guru dan pegawai. Menurut Sallis (2010) fungsi utama pemimpin dalam meningkatkan mutu adalah dengan memberdayakan para guru dan memberi mereka wewenang yang luas untuk meningkatkan pembelajaran para pelajar.

Untuk peningkatan prestasi peserta didik baik prestasi akademik maupun non akademik. Prestasi akademik adalah prestasi siswa dalam mata pelajaran yang diajarkan di sekolah, seperti nilai yang di raih siswa setelah mengikuti ulangan harian, ulangan mid semester, ulangan semester, nilai ujian sekolah atau nilai ujian nasional dan sebagainya. Untuk meningkatkan prestasi non akademik, kepala sekolah dan wakil kepala sekolah bidang kesiswaan mengemukakan yaitu dengan cara mengoptimalkan kegiatan ekstrakurikuler.

Selain itu, untuk meningkatkan mutu sekolah dalam hal prestasi dan kualitas siswa, strategi yang dapat dilakukan sekolah adalah dengan melakukan kerjasama dengan berbagai pihak luar guna menambah wawasan siswa sesuai dengan bidang keahliannya masing-masing. SMK Kansai 
Pekanbaru telah melakukan hubungan kerjasama dengan berbagai pihak, seperti kerja sama dilakukan dengan Dunia Usaha dan Dunia Industri (DUDI), diantaranya: jurusan akuntansi bekerjasama dengan konsultan pajak (Bpk. Sudarno), jurusan teknik komputer dan jaringan bekerjasama dengan Telkom, jurusan teknik instalasi tenaga listrik dan elektronika industri bekerjasama dengan APEI, teknik kendaraan ringan bekerjasama dengan PT. Buana Mobil Sentral Trada, sepeda motor bekerjasama dengan Yamaha Alpha Scorpi, administrasi perkantoran bekerjasama dengan Riau Pos. Selain itu, SMK Kansai juga bekerjasama dengan 100 perusahaan (syarat akreditasi) seperti United Traktor, Pekan Perkasa, dll. Sekolah juga menggunakan tenaga perusahaan sebagai penguji kelayakan siswa (Uji Kompetensi Keahlian). Kerjasama juga dilakukan dengan siswa dikelas tiga yang akan melaksanakan magang di perusahaan dan akan dibina untuk kemudian direkrut diperusahaan tersebut. SMK Kansai Pekanbaru pernah mengirimkan 21 siswa untuk dibina dan direkrut Astra Jakarta. Sudah banyak lulusan SMK Kansai yang bekerja di showroom motor dan mobil di Pekanbaru.

Untuk meningkatkan manajemen mutu, SMK Kansai juga bekerjasama dengan pihak luar negeri seperti Jepang. Pihak Jepang selalu melakukan kunjungan ke SMK Kansai Pekanbaru tiap tahunnya untuk membahas beberapa hal yang dianggap perlu guna meningkatkan mutu sekolah.

Berdasarkan hasil wawancara, penggalian data dan dokumen sekolah, sarana prasarana yang ada di SMK Kansai Pekanbaru telah memenuhi standar sarana prasarana yang seharusnya di miliki sekolah. $\mathrm{U} \quad \mathrm{n} \quad \mathrm{t} \quad \mathrm{u} \quad \mathrm{k}$ memenuhi kebutuhan sarana prasarana sekolah, tentunya diperlukan biaya operasional yang tidak sedikit. Berdasarkan wawancara dengan kepala SMK Kansai Pekanbaru mengenai biaya operasional sekolah diperoleh dari swadaya masyarakat (sumbangan dari masyarakat), dana BOS dari pemerintah, uang kewajiban orangtua (uang komite), seperti uang SPP, uang ujian, dll. Selain itu, biaya operasional dari mitra kerja bersifat bantuan (sponsor) seperti Yamaha memberikan sepeda motor untuk mendukung proses pembelajaran di sekolah. Dengan mengandalkan dana-dana tersebut kepala sekolah berusaha semaksimal mungkin dalam menyukseskan peningkatan mutu di SMK Kansai Pekanbaru. Kepala Sekolah menggunakan dana seoptimal mungkin untuk keberhasilan program peningkatan mutu.

Dalam merencanakan, menyusun, merumuskan strategi-strategi dan programprogram manajemen mutu, kepala SMK Kansai selalu melibatkan seluruh warga sekolah, komite dan juga masyarakat dalam kegiatan peningkatan mutu. Baik itu dalam kegiatan kurikuler maupun kegiatan ekstrakurikuler yang menyangkut peningkatan mutu disekolah.

Berdasarkan wawancara dengan komite diketahui bahwa kepala sekolah selalu berdiskusi dan meminta saran dalam proses perencanaan peningkatan mutu di SMK Kansai Pekanbaru. Komite juga berperan dalam proses perencanaan dengan cara memberikan masukan dan kritikan yang membangun kepada kepala sekolah. Komite menyadari pentingnya peran dalam menyukseskan perencanaan mutu di sekolah. Komite dalam wawancara dengan peneliti menyatakan bahwa komite dan kepala sekolah bekerja sama dalam menyusun strategi manajemen mutu di sekolah untuk meningkatkan mutu sekolah. Komite selalu dilibatkan dalam perencanaan anggaran di sekolah karena kepala sekolah menyadari pentingnya peran komite sekolah. Kepala sekolah menganggap komite sekolah sebagai rekan dalam kerjasama untuk menyukseskan pelaksanaan peningkatan mutu di sekolah.

Hubungan kepala SMK Kansai Pekanbaru terbina sangat baik dengan warga sekolahserta masyarakat dilingkungan sekolah. Seluruh warga sekolah sangat membantu segala kegiatan yang berlangsung. Masyarakat sekitar sekolah sangat mendukung kegiatan peningkatan mutu sekolah. Masyarakat yang diwakili oleh komite sangat 
mendukung segala kegiatan yang dilaksanakan disekolah. Komite dan masyarakat sekitar selalu menanyakan perkembangan kemajuan murid yang sedang belajar di SMK Kansai Pekanbaru. Hal ini sangat berpengaruh terhadap peningkatan mutu yang dilaksanakan SMK Kansai Pekanbaru.

Berdasarkan teori-teori dan penjelasan yang telah dipaparkan dan hasil temuan yang telah didapatkan peneliti, maka dapat dikatakan strategi yang digunakan oleh SMK Kansai Pekanbaru telah sesuai dengan prinsipTotal Quality Management (TQM). Harun menyatakan bahwa peningkatan mutu pendidikan melalui TQM (Total Quality Management) merupakan salah satu cara yang tepat untuk peningkatan kualitas pendidikan dan kualitas organisasi (sekolah).

\section{Implementasi Strategi Manajemen Mutu di SMK Kansai Pekanbaru}

Dari hasil wawancara dengan kepala SMK Kansai Pekanbaru dalam mengimplementasikan strategi manajemen mutu di SMK Kansai Pekanbaru kepala sekolah selalu mensosialisasikan dengan tegas apa saja yang harus dilaksanakan warga sekolah sesuai dengan tanggung jawab yang telah diberikan kepada masing-masing warga sekolah dalam rangka peningkatan mutu pendidikan di SMK Kansai Pekanbaru. Dalam mensosialisasikan sistem manajemen mutu sekolah menyampaikan dalam bentuk lisan, tulisan, dan himbauan. Melalui rapat komite, rapat dewan majelis guru, rapat diawal tahun, rapat di awal semester disampaikan strategi-strategi manajemen mutu yang akan dilaksanakan dan dicapai sekolah serta disesuaikan dengan situasi dan kondisi sekolah.

Kepala sekolah juga melakukan kerjasama dengan warga sekolah dalam sebuah tim yang solid dan kepala sekolah selalu melakukan pengawasan dalam setiap kegiatan disekolah. Pengawasan dilakukan dalam setiap aspek yang dianggap berhubungan dengan peningkatan mutu disekolah. Pengawasan dilakukan guna mengetahui masalah-masalah yang dihadapi oleh guru.
Selain melakukan pengawasan, kepala SMK Kansai Pekanbaru juga melakukan evaluasi secara berekesinambungan guna untuk melihat seberapa besar tingkat ketercapaian strategi manajemen mutu yang telah direncanakan dan disusun pihak SMK Kansai Pekanbaru.

\section{Faktor Pendukung Strategi Manajemen Mutu di SMK Kansai Pekanbaru}

Berdasarkan hasil wawancara dengan kepala sekolah salah satu faktor pendukung pelaksanaan strategi manajemen mutu di SMK Kansai Pekanbaru adalah sumber daya manusia, yaitu tenaga pengajar. Menurut Khasanah sumber daya manusia ini memegang peran yang sangat penting bagi kelangsungan proses kegiatan dan juga pelayanan jasa pendidikan di sekolah(Khasanah, 2015).

Di SMK Kansai Pekanbaru tenaga pengajar yang berpendidikan memiliki kualifikasi S1 dan S2 sesuai dengan kualifikasi bidang studi yang diajarkannya. Kualifikasi pendidikan guru yang sesuai dengan bidang studi yang di ajarkannya, akan dapat meningkatkan kualitas dan kinerja guru dapat melaksanakan tugasnya sebagai tenaga pendidik.

Sarana dan prasarana juga menjadi faktor pendukung dalam implementasi strategi manajemen mutu di SMK Kansai Pekanbaru. Sekolah terus meningkatkan kualitas dan kuantitas sarana dan prasarana sekolah. Hal ini dilakukan agar proses pembelajaran di sekolah tidak terganggu dan berjalan lancar.

Faktor lain yang mendukung peningkatan mutu pendidikan di SMK Kansai Pekanbaru adalah iklim sekolah dan lingkungan masyarakat yang kondusif. Suasana kebersamaan, koordinasi yang baik antar warga sekolah dan lingkungan masyarakat, merupakan suasana yang sangat mendukung untuk terlaksananya program peningkatan mutu di SMK Kansai Pekanbaru.

\section{Faktor Penghambat Implementasi Strategi Manajemen Mutu di SMK Kansai Pekanbaru \\ Selain faktor pendukung, ada juga faktor penghambat yang dihadapi kepala SMK Kansai}


Pekanbaru. Berdasarkan wawancara dengan kepala sekolah mengenai faktor penghambat yang kepala sekolah hadapi dalam pelaksanaan strategi manajemen mutu di sekolah adalah Sumber Daya Manusia (SDM). Sumber daya manusia, dalam hal ini guru, selain menjadi faktor pendukung juga menjadi faktor penghambat dalam implementasi strategi manajemen mutu di sekolah. Hal ini dikarenakan terdapat beberapa guru yang tidak mau bekerjasama. Kepala sekolah menyadari bahwa setiap guru memiliki sifat dan karakter yang berbeda-beda.

Hal ini senada dengan hasil penelitian yang diperoleh Munir (2014), yaitu kendala yang dihadapi dalam melaksanakan sistem manajemen mutu di SMKN 1 Buduran yakni kurangnya konsistensi dan kepedulian sumber daya manusia di sekolah tersebut.

Dalam implementasi strategi manajemen mutu di sekolah guru memiliki peran yang sangat penting. Setiap guru harus bertanggung jawab atas tugas-tugas yang diberikan kepadanya. Selain mengajar dan mendidik siswa di kelas, guru juga memiliki tugas dalam hal meningkatkan mutu sekolah. Guru dan warga sekolah lainnya merupakan pelaksana dan objek untuk mencapai tujuan (mutu) harus memiliki kesadaran mutu, komitmen dan tanggung jawab serta terlibat secara aktif mewujudkan tercapainya mutu yang diharapkan. Ketercapaian mutu tidak hanya tanggung jawab pimpinan (kepala sekolah dan wakil kepala sekolah) tetapi semua elemen ikut berperan aktif dan bertanggung jawab atas tercapainya mutu. Dengan demikian kerja tim dan keterlibatan guru dan pegawai secara penuh menjadikan mutu sebagai kenyataan.

\section{Cara Mengatasi Faktor Penghambat Strategi Manajemen Mutu di SMK Kansai Pekanbaru}

Berdasarkan hasil wawancara dengan kepala sekolah mengenai cara mengatasi faktor penghambat implementasi manajemen mutu di SMK Kansai Pekanbaru, kepala sekolah selaku pimpinan selalu berusaha untuk menjadi contoh bagi guru dan pegawai sekolah. Kepala sekolah berusaha untuk mendekati guru dan pegawai dengan cara berbaur dengan bawahan. Kepala sekolah berusaha untuk mengajak, merangkul dan membiasakan diri guru dan pegawai untuk selalu bekerja sama agar strategi manajemen mutu untuk meningkatkan mutu sekolah dapat tercapai. Selain itu, kepala sekolah juga memberikan reward kepada guru yang disiplin dan menjalankan tugas pokoknya dengan sangat baik serta mendukung sekolah dalam peningkatan manajemen mutu sekolah.

Dalam mengatasi faktor penghambat tersebut, kepala sekolah juga menyadari akan tugas yang diembannya, termasuk dalam hal bertanggungjawab atas guru yang mengajar di sekolah tersebut. Hal ini sesuai dengan Wahjosumidjodalam Banun (2016) yang menyatakan bahwa tugas-tugas kepala sekolah diantaranya: (1) kepala sekolah bertindak dan bertanggungjawab atas segala tindakan yang dilakukan oleh bawahan, (2) dengan segala keterbatasan seorang kepala sekolah harus dapat mengatur pemberian tugas secara tepat serta dapat memprioritaskan bila terjadi konflik antara kepentingan bawahan dengan kepentingan sekolah, (3) kepala sekolah harus dapat memecahkan persoalan melalui satu analisis, kemudian menyelesaikan persoalan dengan satu solusi yang fleksibel, (4) dalam lingkungan sekolah sebagai suatu organisasi di dalamnya terdiri dari manusia yang mempunyai latar belakang yang berbeda-beda yang bisa menimbulkan konflik untuk itu kepala sekolah harus jadi penengah dalam konflik tersebut, (5) kepala sekolah harus dapat membangun hubungan kerjasama melalui pendekatan persuasi dan kesepakatan.

\section{SIMPULAN DAN SARAN}

Berdasarkan hasil temuan penelitian, analisis serta pembahasan yang telah dilakukan, maka dapat disimpulkan bahwa:

1. Strategimanajemen mutu yang direncanakan, disusun dan diimplementasikan SMK Kansai Pekanbaru telah sesuai dengan prinsipTotal Quality Management (TQM). Kepala 
sekolah selalu melibatkan seluruh warga sekolah dalam meningkatkan mutu sekolah, menyusun program yang merujuk pada visi dan misi sekolah, selalu berkerja dalam tim yang solid, fokus pada pelanggan, selalu berkomitmen jangka panjang, memberi kebebasan yang terkendali kepada guru, melakukan pelatihan-pelatihan, berusaha meningkatkan prestasi siswa dibidang akademik dan non akademik, serta selalu melakukan supervisi secara berkesinambungan.

2. Dalam mengimplementasikan strategi manajemen mutu di SMK Kansai Pekanbaru, kepala sekolah selalu mensosialisasikan dengan tegas apa saja yang harus dilaksanakan warga sekolah sesuai dengan tanggung jawab yang telah diberikan kepada masing-masing warga sekolah dalam rangka peningkatan mutu pendidikan di SMK Kansai Pekanbaru. Dalam proses implementasi, kepala sekolah juga melakukan supervisi setiap bulannya dan melakukan evaluasi secara berkesinambungan untuk melihat seberapa besar tingkat ketercapaian strategi manajemen mutu yang telah direncanakan dan disusun pihak SMK Kansai Pekanbaru.

3. Dalam proses implementasi terdapat faktor pendukung implementasi strategi manajemen mutu di SMK Kansai, yaitu tenaga pengajar yang berpendidikan kualifikasi S1 dan S2 sesuai dengan kualifikasi bidang studi yang diajarkannya, iklim sekolah dan lingkungan masyarakat yang kondusif serta sarana dan prasarana sekolah. Suasana kebersamaan, koordinasi yang baik antar warga sekolah dan lingkungan masyarakat, merupakan suasana yang sangat mendukung untuk terlaksananya program peningkatan mutu pendidikan di SMK Kansai Pekanbaru.

4. Dalam proses implementasi strategi manajemen mutu di SMK Kansai Pekanbaru juga terdapat faktor penghambat, yaitu masih terdapat beberapa guru yang tidak mau untuk bekerjasama dalam hal peningkatan mutu sekolah.
5. Untuk mengatasi faktor penghambat tersebut, kepala sekolah melakukan pengawasan terhadap guru dan memberikan reward bagi guru yang disiplin dan menjalankan tupoksi dengan baik.

Terkait dengan kesimpulan di atas, maka penulis menyarankan sebagai berikut:

1. Kepala sekolah untuk terus mengawasi kinerja guru dengan memberikan penghargaan kepada guru yang berprestasi, memberikan perhatian baik dari segi materi maupun non materi, sehingga guru merasa dihargai dan memiliki potensi terhadap peningkatan sekolah.

2. Kepala sekolah agar senantiasa memotivasi guru dan mencari solusi yang tepat terhadap permasalahan yang dihadapi guru dalam meningkatkan mutu pendidikan di sekolah serta terus melakukan pelatihan, pembekalan dan pembinaan kepada para guru agar senantiasa meningkatkan kompetensi mereka dalam manajemen sekolah, sehingga akan mampu menjadi sebagai pendidik yang profesional.

3. Agar strategi peningkatan mutu pendidikan sekolah dapat benar-benar berjalan efektif maka diperlukan dukungan dari seluruh stakeholder penyedia jasa pendidikan maupun stakeholder pengguna jasa pendidikan.

\section{DAFTAR PUSTAKA}

Arcaro, J.S. (2006).PendidikanBerbasisMutu :Prinsip-prinsipPerumusandan Tata LangkahPenerapan. Yogyakarta: PustakaPelajar.

Banun, S., Yusrizal, dan Nasir, U. (2016). Strategi Kepala Sekolah dalam Meningkatkan Mutu Pendidikan pada SMP Negeri 2 Unggul Mesjid Raya Kabupaten Aceh Besar. Jurnal Admisnistrasi Pendidikan. vol 4 no. 1. hal 137-147.

Danim, S. (2007). Visi Baru Manajemen Sekolah. Jakarta: Bumi Aksara.

Ibnugraha.(2012). Pelaksanaan Sistem 
Manajemen Mutu(SMM) ISO 9001-2008 di SMK Negeri 2 Pengasih Kulon ProgoTahun 2012. Jurnal Pendidikan Teknologi dan Kejuruan.vol 21 no.1 hal.23-29

Khasanah, A. (2015). Pemasaran Jasa Pendidikan Sebagai Strategi Peningkatan Mutu di SD Alam Baturraden. Jurnal eLTarbawi. vol. 8 no. 2. hal 161-176.

Mulyasa, E. (2007). Menjadi Kepala Sekolah Profesional dalam Menyukseskan MBS dan KBK. Bandung : PT Remaja Rosda Karya.
Munir, S. dan Nurhimahyanti, D. (2014). Implementasi Sistem Manajemen Mutu ISO 9001:2008 di SMK Negeri 1 Buduran Sidoarjo. Jurnal Inspirasi Manajemen Pendidikan. vol 3 no. 3 hal. 152-155.

Sallis, E. (2010). Total Quality Management in Education. Yogyakarta : PT IRCiSoD.hal.174.

Zamroni.(2007). Meningkatkan Mutu Sekolah. Jakarta : PSAP Muhamadiyah. 